rev.relac.int.estrateg.segur.11(2):93-109,2016

\title{
ÁFRICA, A NOVA FRONTEIRA ESTRATÉGICA NO DESENVOLVIMENTO GLOBAL: A GEO-POLÍTICA DE CABO VERDE NO CONTEXTO DA CEDEAO*
}

\author{
Nataniel Andrade Monteiro**
}

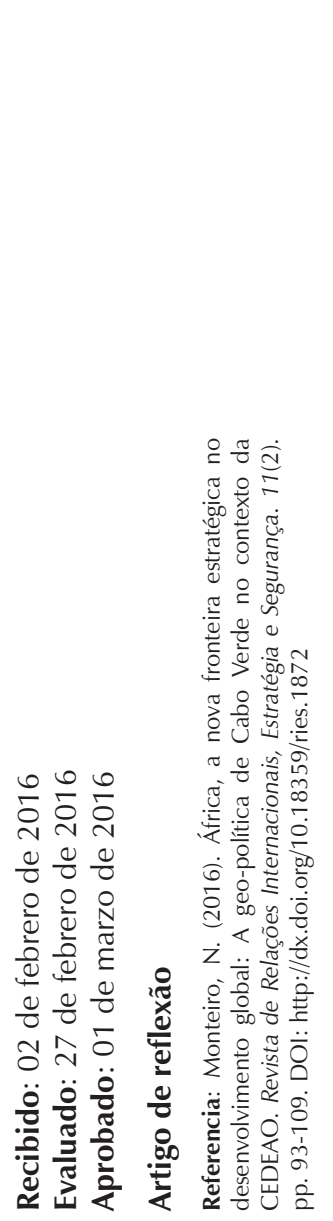

\section{RESUMO}

$\mathrm{O}$ artigo procura compreender os desafios de desenvolvimento que se impõem a Cabo Verde, passados os trinta e oito anos da assinatura do Tratado Constitutivo para a sua integração na Comunidade Econômica dos Estados da África Ocidental (CEDEAO). O raciocínio central é o de que a estratégia de Cabo Verde após a independência passou por uma aposta ativa nas relações internacionais, essencialmente na mobilização da ajuda pública para o desenvolvimento. Esta mobilização baseava-se no cumprimento das obrigações internacionais e dos princípios da reciprocidade diplomática, expressamente com a Europa, os Estados Unidos da América e a China. Procedemos a uma pesquisa explorativa que é complementada por uma análise interpretativa, de

\footnotetext{
Este artigo é resultado de um projeto em curso no Centro de Investigação em Desenvolvimento Local e Ordenamento do Território (CIDLOT) da Universidade de Cabo Verde (Uni-CV).

** Investigador no Centro de Investigação em Desenvolvimento Local e Ordenamento do Território (CIDLOT- Uni-CV). Licenciado em Ciência Política e Mestre em Ética e Filosofia Política, Universidade de Cabo Verde (UCV). Endereço eletrônico: nataniel.monteiro@ student.unicv.edu.cv
} 
modo a responder às questões-chaves desta investigação. Como recomendação geoestratégica, acreditamos que, num contexto abalado pela crise financeira internacional, que tem afetado diretamente ou indiretamente os parceiros estratégicos de Cabo Verde, seria vantajoso que o arquipélago centralizasse novamente a sua geo-política de integração na África, particularmente no âmbito da Comunidade Econômica dos Estados da África Ocidental, aproveitando o continente como nova fronteira de desenvolvimento.

Palavras-chave: Cabo Verde; CEDEAO; Desenvolvimento; Geo-política; Integração Regional.

\section{ÁFRICA, LA NUEVA FRONTERA ESTRATÉGICA EN EL DESARROLLO GLOBAL: LA GEOPOLÍTICA DE CABO VERDE EN EL CONTEXTO DE LA CEDEAO}

\section{RESUMEN}

El artículo busca comprender los desafíos del desarrollo que se imponen a Cabo Verde, pasados los treinta y ocho años de la firma del Tratado Constitutivo para su integración en la Comunidad Económica de los Estados de África Occidental (CEDEAO). El raciocinio céntrico de la estrategia de Cabo Verde después de la independencia pasó por una apuesta activa en las relaciones internacionales, esencialmente en la movilización de la ayuda pública para el desarrollo. Esta movilización basada en la aceptación de las obligaciones internacionales y de los principios de la reciprocidad diplomática, expresamente con Europa, los Estados Unidos de América y China. Procedemos a una investigación exploratoria que es complementada por un análisis interpretativa, de modo a responder a las cuestiones clave de esta investigación. Como recomendación geoestratégica, creemos que en un contexto sacudido por la crisis financiera internacional que ha afectado directa o indirectamente los compañeros estratégicos de Cabo Verde. Sería ventajoso que el archipiélago (re)centralizase su geopolítica de integración en África, particularmente en el ámbito de la Comunidad Económica de los Estados de África Occidental, aprovechando el continente como nueva frontera de desarrollo.

Palabras clave: Cabo Verde; CEDEAO; Desarrollo; Geopolítica; Integración Regional. 


\title{
AFRICA, THE NEW FRONTIER IN GLOBAL DEVELOPMENT: THE GEOPOLITICS OF CAPE VERDE IN THE CONTEXT OF ECOWAS
}

\begin{abstract}
The article seeks to understand the development challenges necessary to Cape Verde, after thirty-eight years of the signing of the Treaty of incorporation for their integration in the Economic Community of West African States (ECOWAS). The reasoning is that the strategy of Cape Verde after independence passed by an active bet in international relations, particularly in the mobilization of public aid for development. This mobilization was based on international obligations and the principles of reciprocity, particularly with Europe, the United States of America and China. We have an exploratory research that is complemented by an interpretative analysis, in order to respond to the key issues of this investigation. As geostrategic recommendation, we believe in an environment affected by the international financial crisis that has affected directly or indirectly the strategic partners of Cape Verde, would be advantageous to the archipelago to (re) centralize its geopolitics of integration in Africa, particularly in the context of the Economic Community of West African States, taking advantage of the Mainland as new frontier of development.
\end{abstract}

Keywords: Cape Verde; ECOWAS; Development; Geopolitics; Regional Integration.

\section{Introdução}

Com uma população residente de aproximadamente 500000 habitantes, Cabo Verde emerge no espaço do Atlântico com valor geoestratégico entre a África, Europa e as Américas (Correia e Silva, 1996). O arquipélago conquistou respeito, autonomia e reconhecimento no panorama internacional após a independência. Um dos primeiros passos foi a não permissão da instalação de bases militares, quer seja do bloco capitalista, quer seja do bloco socialista no período da Guerra Fria (1945 a 1989), aderindo astuciosamente ao Movimento dos Países Não-Alinhados (Graça, 2014). A estratégia de soft power permitiu ao país, durante os quinze anos do regime de partido único (1975-1990), a conquista de uma imagem de Estado estável e viável na África. Propensão que tem acompanhado o arquipélago ainda na segunda República (a partir de 1991), proporcionando-lhe benefícios no que se refere a doações, ajuda pública ao desenvolvimento, empréstimos e investimentos de potências mundiais. 
Que alternativas são mais viáveis para o desenvolvimento e sustentabilidade econômica de Cabo Verde, no contexto abalado pela crise financeira internacional que afeta os seus tradicionais parceiros, em especial a União Europeia (UE)? É viável, a cooperação e centralização da geopolítica de integração de Cabo Verde na plataforma da CEDEAO? A posição geoestratégica de Cabo Verde no Atlântico é vantajosa para o país para sujeitar as fragilidades socioeconômicas de um pequeno Estado insular e periférico? Como se pode Cabo Verde tirar partido da sua posição geoestratégica? São algumas questões de partida que procuramos responder através do método qualitativo, baseando-se principalmente nas abordagens interpretativas e à pesquisa explorativa, para que as conclusões tiradas auxiliem na construção de um novo campo de investigação.

Assim sendo, surgem algumas proposições hipotéticas: primeira, Cabo Verde é tida no contexto africano como uma referência de um bom governo, o que pode fazer do país, apesar de ser pequeno, insular e economicamente dependente, um modelo para os demais Estados da África Ocidental, tornando-se num parceiro que coopera no desenvolvimento da CEDEAO e do continente africano; segunda, Cabo Verde pode, pela sua posição geoestratégica, transformarse numa plataforma de prestação de serviços, disputando o espaço geoeconômico da CEDEAO de modo que os ganhos possam reverter também para o reforço de cooperação com a África.

A presente pesquisa constitui uma ajuda para o estudo da geo-política de Cabo Verde no contexto africano, uma área que pela fraca doutrina de produção científica poucos pesquisadores se têm debruçado sobre o tema. A originalidade desta investigação encontra-se precisamente na possibilidade de se aproximar o universo teórico da realidade caboverdiana, contribuindo para uma análise inter-subjetiva, alternativa e flexível e possibilitando compreender uma conjuntura geo-histórica peculiar que se demarque no contexto da África Ocidental.

Através desta investigação é possível constatar que a localização geoestratégica no Atlântico Sul permitiu que Cabo Verde, desde a independência (1975), cooperasse estrategicamente com a Europa, América e hoje, de forma promissora com a China, projetando-se no cenário sub-regional, regional e internacional (Reis, 2010). Esta aproximação de Cabo Verde aos tradicionais parceiros é alvo de muitas críticas, na medida em que as relações internacionais do país devem ser divida em quatro partes, África, Europa, EUA e China. Porém, dando uma atenção prioritária ao continente africano, uma vez que seria vantajoso para Cabo Verde uma maior projeção e integração regional na CEDEAO, de modo a 
tirar vantagens no sistema global, valorizando-se mutuamente - Cabo Verde e a comunidade - no sentido de potencializar as suas aspirações.

\section{Geo-política e Desenvolvimento.}

É consensual, no âmbito dos estudos da geo-política, que foi no início do século XX, que o cientista político sueco Rudolf Kjellén, professor das Universidades de Gotemburgo e Uppsala, utilizou pela primeira vez - na sua forma original - o termo geo-política, inspirando-se na obra Geografia Política (1897) de Friedrich Ratzel (Costa, 2008). A perspectiva central de Kjellén é a de que o Estado se assemelha a um organismo biológico em constante expansão, que procura, seja por colonização ou conquista, expandir o seu espaço geográfico (Costa, 2008). A definição de geopolítica mais aceitada pelos estudiosos do tema é a de Kjellén, que considera ser esta uma disciplina que estuda a influência que o espaço geográfico tem sobre o homem e, consequentemente, sobre a ação política, baseado na ideia de que os ambientes geográficos moldam o homem (Defarges, 2003).

A data precisa em que o termo geopolítica foi utilizado pela primeira vez é bastante discutida no âmbito académico-científico. Sem embargo, acredita-se que Kjellén utilizou-se o termo em 1900, numa comunicação, denominada Introdução à geografia da Suécia, apresentada no âmbito das conferências destinadas à Universidade de Gotemburgo (Korinman, 1990). Porém, o processo de afirmação da geo-política, enquanto disciplina das ciências humanas, foi conturbado e ficou conotado à expansão do regime Nazista na Alemanha, que culminou na tragédia da segunda Guerra Mundial. A receptividade ao discurso imperialista e autoritário de Kjellén foi bastante expressiva, não só na Suécia, como também na Alemanha, pois as ideias do sueco e o termo geo-política tornaram-se rapidamente populares (Korinman, 1990). Esta rápida absorção pelos alemães foi consequência, acima de tudo, à profunda simpatia e admiração que Kjellén tinha pela Alemanha Imperial, ele próprio, aliás, casado com uma alemã. Por causa desta profunda relação e conotação da geo-política ao imperialismo alemão, a geo-política tornou-se numa ciência bastante criticada nos anos seguintes (Mello, 2015).

Esta tendência, centralizou novamente no final da década de 1980, e a geopolítica ganha alguma notoriedade, tornando-se moda, principalmente entre os analistas de relações internacionais, e passando a ser usada, para se referir praticamente a todas as discussões políticas e econômicas internacionais (Vesentini, 2008). A notoriedade, segundo Tuathail, Dalby e Routledge (2006), está relacionada com três aspectos fundamentais: [i] a geo-política tem atraído a atenção de cada vez mais políticos, acadêmicos, pesquisadores e jornalistas pelo 
fato de lidar constantemente com questões de poder e conflito no plano internacional; [ii] a geo-política parece transformar a falta de clareza das relações internacionais num quadro aparentemente claro, pois procura explicar de forma coerente as coisas que parecem ser mais complexas; [iii] e por último, aponta e prevê a evolução mundial num determinado sentido, numa espécie de discurso profético.

A geo-política está longe de ser um campo de conhecimento unitário, pois tem múltiplas histórias relevantes, simultaneamente paralelas e concorrenciais, (Fernandes, 2003). É neste quadro, que se destaca uma multiplicidade de abordagens e correntes teóricas, procurando ter foco essencialmente em duas correntes que congregam os principais teóricos fundadores desta disciplina acadêmico-científica: [i] a 'teoria do Estado orgânico' que emerge da perspectiva do darwinismo social, e tem como principais teóricos fundadores Friedrich Ratzel e Rudolf Kjellen. O primeiro é um dos mais influentes geógrafos da Europa novecentista: nasceu em 1844 e foi professor e detentor da cátedra de Geografia na prestigiada universidade de Leipzig (1886). Formado inicialmente em biologia e química, as obras - "Antropogeografia", (1882), "Geografia Política" (1897) e "O Espaço Vital" (1901) - e o pensamento de Ratzel foram fortemente associados às concepções evolucionistas e biológicas do Estado e da sociedade que progressivamente se difundiram pelo campo das Ciências Sociais, após a publicação da obra "A Origem das Espécies" (1859) de Charles Darwin (Fernandes, 2003). Ratzel defende que as atividades da sociedade e do Estado deveriam ser vistas na perspectiva de que esses dependem diretamente do solo em o qual vivem, ou seja, do espaço vital.

Revolucionário da geografia do seu tempo, Ratzel influenciou Rudolf Kjellen e outros geógrafos importantes, fora do espaço cultural germânico, como o francês Paul Vidal de la Blanche (Fernandes, 2003). Rudolf Kjellen concentra-se principalmente na ideia de que os Estados precisam constantemente de espaços geográficos para se fortalecerem. Ele deu uma inigualável contribuição a esta corrente teórica, defendendo que só conseguirão sobreviver na terra os Estados mais fortes e extremamente poderosos (Glassner, 2003). Nesta ideia, defende o cientista político sueco que a garantia de espaços geográficos seria vital para a sobrevivência dos Estados, o que ocasiona uma crescente competição entre os mesmos, onde os mais fortes e os maiores terão mais possibilidades de sobrevivência em relação aos menores e mais fracos. [ii] uma segunda corrente teórica é geo-estratégia fundada pelo norte-americano Alfred Mahan e o britânico Halford Mackinder que se basearam mais em fatos geográficos e políticos. Alfred Mahan, almirante, oficial da marinha e historiador norte- 
americano, nasceu no ano de 1840, tendo sido o expoente máximo da "teoria do poder marítimo" que foi importante e muito influente no final do século XIX e início do século XX nos EUA (Mello, 2015). O norte-americano defendeu a importância do poder marítimo na supremacia histórica dos EUA, onde, no âmbito da segurança e desenvolvimento, as marinhas foram percebidas como símbolos do prestígio e do poder, na medida em que constituem instrumentos políticos relevantes nas relações com outros atores (Crowl, 1986). O almirante norte-americano privilegiou no quadro da política internacional dos EUA, as ligações entre o poder marítimo, o poder nacional e a hegemonia mundial, considerando que os EUA deveria traçar como estratégia de sobrevivência e prevalência a hegemonia e o controle sobre o seu continente no sentido de impedir a expansão do Japão no Extremo Oriente e centrar-se, em prazo médio, nas questões marítimas, conquistando a supremacia marítima britânica (Glassner, 2003).

Outro importante fundador desta corrente teórica é o britânico Halford Mackinder com a sua teoria "geopolítica e estratégica do poder terrestre". Mackinder atribui na sua teoria, importância ao "coração continental" e o papel estratégico desta região pivô (Pivot Area) na política das grandes potências. De fato, "o termo Pivot Area designava o grande núcleo do continente euro-asiático e os seus limites correspondiam, em linhas gerais, ao gigantesco território da Rússia" (Mello, 2015, p. 16). O tal "coração continental" (Heartland) é uma região que se situa entre a Rússia e a Alemanha que seria o centro vital da Eurásia (massa terrestre que forma em conjunto a Europa e Ásia). Para Mackinder, quem conseguir dominar o "coração continental", dominará também o mundo, visto ser uma região estratégica pese às ameaças de eventuais ataques militares e de potências marítimas (Glassner, 1993).

A geo-política é entendida como uma disciplina das ciências humanas que procura compreender as relações recíprocas entre o poder do Estado e o espaço geográfico, ou seja, procura responder até que ponto as ações dos Estados nacionais são ou não determinadas pela situação geográfica (Castro, 1961). As ações dos Estados nacionais assentam em dois pilares fundamentais da geo-política: o poder e o desenvolvimento. Constatando a perspectiva de Weber (2015), acreditamos que, em última instância, o processo de desenvolvimento econômico também constitui uma luta de dominação. Por outras palavras, não existe desenvolvimento econômico que não envolva uma luta de poder e pelo poder. Acreditamos, que os Estados nacionais procuram, através da geo-política, a luta pela dominação de novos espaços geográficos territórios econômicos - regionais e internacionais, seguindo logicamente os seus instrumentos de poder (os 
recursos econômicos e militares). $\mathrm{O}$ desenvolvimento, deste modo, tornase uma exigência mundial, onde, após a Segunda Guerra Mundial a sua concepção se igualou à de progresso material, um estágio a ser atingido por todos os países do mundo (Pizzi 2005). O desenvolvimento, conceito polissémico e objeto de uma definição bastante discutida, estaria relacionado com a necessidade de criar instrumentos competitivos - tanto para fins econômicos como militares - onde, os Estados, ao promoverem desenvolvimento, pese às dificuldades políticas - de natureza militar e econômicas a que estão submetidas teriam maior preparação. Percebemos então que o desenvolvimento não se conforma como um fim em si mesmo, senão como um meio econômico de se manter firme na disputa entre os Estados por poder, que simultaneamente anima e delimita as possibilidades de desenvolvimento (Lopes da Cunha \& Appel, 2014).

Se, no âmbito da geo-política, os Estados nacionais precisam de espaços geográficos, (espaços vitais) para a sobrevivência, significa que a competição e disputa entre esses são praticamente inevitáveis. É por isso mesmo que, quanto maior for a competição entre os Estados, maior é a necessidade de implementação de projetos de desenvolvimento, porque a geração de riqueza está intimamente relacionada com o contexto geo-político (Lopes da Cunha \& Appel, 2014). Ratzel e Kjéllen chamam a atenção para o papel da infraestrutura - que constitui a base de apoio fundamental para o desenvolvimento de setores e espaços econômicos - na colisão político-territorial e no aproveitamento do potencial geográfico de um espaço territorial (Backheuser, 1952).

O caso de Cabo Verde não é diferente, o pilar fundamental da geo-política é o desenvolvimento do arquipélago, onde se têm verificado grandes investimentos na infraestruturação e desenvolvimento de setores estratégicos como, entre outros, a educação, saúde, mar e o turismo. Desde a independência nacional, perante a fragilidade da economia e precariedade de recursos naturais, o país tem definido como prioridade o desenvolvimento socioeconômico, ligando-se às regiões geográficas, o que the permite a estabilidade macroeconômica.

Entretanto, perante fenômenos internacionais contundentes, em especial a crise econômica-financeira que tem afetado parceiros estratégicos do arquipélago, acreditamos que seria vantajoso para o país a reunir no mesmo centro a geo-política de integração na África, aproveitando o continente como nova fronteira de desenvolvimento, que, aliás, tem crescido a uma média anual significativa.

\section{Uma abordagem geo-histórica sobre a CEDEAO}

Palco da colonização de antigos Impérios Europeus, a África Ocidental 
subdivide-se em duas regiões, a do Sahel que abarca países (de oeste para leste) como Gana, Senegal, Cabo Verde, Mauritânia, Burkina Faso, Mali e Níger; e a região costeira que abrange países como Guiné-Bissau, Guiné Conarki, Serra Leoa, Libéria, Costa do Marfim, Togo, Benin, GuinéEquatorial e Nigéria, atigindo um total de dezesseis países.

A conferência de Berlim (entre 1884 e 1885) ou o tratado de partilha dos territórios africanos pelas antigas potências coloniais europeias desencadeou conflitos territoriais e guerras civis na região da África Ocidental, representando uma era de novas conformações geográficas e territoriais (Boahen, 2010; Uzoigwe, 2010; Ki-Zerbo, 2010). Ante este cenário, os países da região procuraram criar organizações e instituições regionais com o objectivo de projetar o desenvolvimento socioeconômico. É neste quadro que surge, através do Tratado de Lagos de 28 de Maio de 1975, a Comunidade Econômica dos Estados da África Ocidental (CEDEAO), cujo objetivo central foi o de estabelecer uma união de alfândega e um mercado comum. A comunidade, ao priorizar o setor econômico, não deixou de investir em outros importantes setores, como a política, a defesa e a segurança. A propósito, o processo de integração regional, não deve ser feita exclusivamente com base em abordagens econômicas, mas também acompanhado de objetivos e abordagens políticas e sociais, ou seja, os fatores políticos, econômicos e sociais devem estar inter-relacionados (Badi, 2001).

O projeto da criação da CEDEAO, que teve influência diplomática significativa da Nigéria, estabeleceu como objetivo, a promoção do comércio, da cooperação e do desenvolvimento econômico da região. A partir dos finais dos anos setenta, a comunidade começou a promover outras áreas de integração como por exemplo, a segurança e a defesa, fruto da preocupação com os sucessivos golpes de Estado e conflitos civis registados na região. A materialização do projeto aconteceu em 1975 com a assinatura do Tratado Constitutivo por quinze Estados-membros (Benim, Burkina Faso, Costa do Marfim, Gâmbia, Gana, Guiné, Guiné-Bissau, Libéria, Mali, Mauritânia, Níger, Nigéria, Senegal, Serra Leoa e Togo), com exceção de Cabo Verde, já que esse só aderiu dois anos após a independência, em 1977. Não obstante, verifica-se que por motivos históricos geográficos, culturais, linguísticos e de governo, as Nações da África Ocidental ainda lidam mal com a integração regional, que aceitam mais como destino do que como projeto concluindo informação de boa qualidade e vontade democraticamente construída (Tolentino, 2013). Na verdade, os principais personagens que tentaram promover a integração na CEDEAO falharam, uma vez que esse processo viria a revelar-se lento e com fracos resultados devido à incapacidade de 
promover incentivos para a cooperação econômica entre os Estados-membros (Zannou, 2010).

A CEDEAO conta atualmente com quinze Estados-membros, já que em 2002 a Mauritânia abandonou a organização. A comunidade, onde Cabo Verde é o mais pequeno em termos territoriais $\left(4033 \mathrm{~km}^{2}\right)$ e populacionais (aproximadamente 500000 habitantes residentes), é constituída por uma massa de terra total de 5,112,903 milhas quadradas e uma população de aproximadamente 251.646.263 pessoas, com um produto interno bruto combinado ao redor de 342,5 mil milhões de dólares. Cabo Verde, devido às suas particularidades geográficas e territoriais e a sua provável importância nesta região, num contexto onde a segurança, a paz e o desenvolvimento têm sido preocupações constantes, é atualmente objeto de um intenso debate científico na academia.

\section{Retomada da centralização da geo- política de Cabo Verde na CEDEAO: Desafios num contexto de incertezas}

O arquipélago de Cabo Verde, localizado sensivelmente a $500 \mathrm{~km}$ de costa ocidental africana, ao largo do Senegal, entre os paralelos $17^{\circ}$ $12^{\prime}$ e 14 o $48^{\prime}$ de latitude Norte, e os meridianos 22o $44^{\prime}$ e $25^{\circ} 22^{\prime}$ de longitude Oeste, é constituído por um conjunto de dez ilhas e treze ilhéus, dividido em duas regiões geográficas, a do Sotavento e a do Barlavento, consoante a posição face ao vento. A região do Sotavento é constituída pelas ilhas Brava, Fogo, Santiago e Maio; e os ilhéus Santa Maria, Grande, Luís Carneiro e de Cima. A região do Sotavento é constituída pelas ilhas Santo Antão, São Vicente, Santa Luzia, São Nicolau e Boavista; e os ilhéus Boi, Pássaros, Branco e Raso, Rabo de Junco, Curral de Dado, Fragata, Chano e Baluarte.

Perante algumas limitações, como a insularidade, vulnerabilidade do território e falta de recursos naturais e econômicos, Cabo Verde procurou estrategicamente afirmar-se no plano internacional e maximizar as potencialidades conseguidas graças à vinculação a organizações e instituições sub-regionais, regionais e internacionais, como a União África (UA), a Comunidade Econômica dos Estados da África Ocidental (CEDEAO), a Organização da Nações Unidas (ONU), o Fundo Monetário Internacional (FMI) e a Organização Mundial do Comércio (OMC) (Mourão, 2003). De fato, o recurso às organizações internacionais e "a inserção natural na CEDEAO e na União Africana, assim como a assunção das múltiplas atribuições à região africana, ao eixo insular atlântico (Islândia - Maldivas) e ao continente americano darão maior sentido e peso a Cabo Verde" (Tolentino, 2007, p. 124).

Devido aos prováveis laços históricos e ideológicos, a relação entre Cabo Verde e o continente africano, nos quinze anos do regime de partido úni- 
Figura 1: O mapa do arquipélago de Cabo Verde

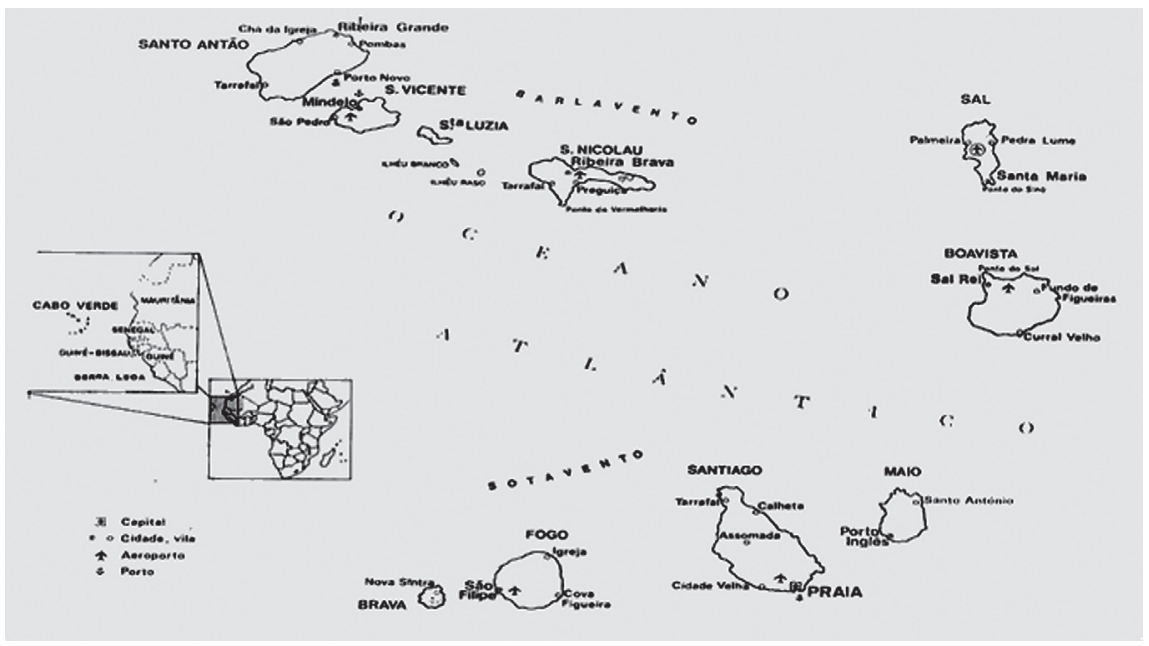

Fonte: Adaptado de Santos, M. E. M. (2007). História Concisa de Cabo Verde. Lisboa/Praia: IICT/IIPC.

co (1975-1990) no arquipélago, era muito mais sólida, acima de tudo com a Guiné-Bissau, visto que partilhavam um projeto comum de luta pela libertação contra a colonização portuguesa. Além deste fato, há que destacar um outro importante marco histórico que serviu de alguma forma para reforçar a relação entre Cabo Verde e África: trata-se do papel do arquipélago na resolução do conflito na África Austral (entre 1966 e 1989), especificamente entre Angola e África do Sul. Porém, na sequência do golpe de Estado no território da Guiné-Bissau na década de oitenta, realizado por João Bernardo Vieira, a ligação político-institucional entre Guiné-Bissau e Cabo Verde chegou ao fim, visto que este ultimo condenou vigorosamente o referido golpe, procedendo de imediato em Ja- neiro de 1981 ao desligamento com o projeto binacional, o que se consuma com revisões constitucionais, nomeadamente suprindo da Constituição da República de Cabo Verde (CRCV) os capítulos, seções e subseções que legitimavam esta união.

Mesmo contra a retórica dos dirigentes políticos, de fato verifica-se que nas últimas décadas, principalmente a partir dos anos noventa, a relação de Cabo Verde com a África esfriou um pouco, embora oarquipélago nãotenha deixado de cooperar com o continente no quadro das organizações subregionais, regionais e internacionais. Apesar de a CRCV considerar que o Estado cabo-verdiano deve empenhar no reforço da unidade e da integração africana (CRCV, 1992, Artigo 11으, n.음 
7), o que tem igualmente norteado programas dos sucessivos Governos, a prática político-diplomática não tem correspondido à esta expectativa. A candidatura no início de 2015, por parte Cristina Duarte, Ministra cabo-verdiana das Finanças e do Planejamento, à presidência do Banco Africano de Desenvolvimento (BAD) veio aprofundar a certeza de que nos últimos anos houve um afrouxamento das relações entre Cabo Verde e África. O diretor da sua campanha, Jorge Brito, defende que falta uma vontade política dos dirigentes políticos caboverdianos de conhecer o continente africano, e uma política adequada de integração sub-regional, tendo esses fatores acabado por, de alguma forma, afetar, o desempenho da Ministra caboverdiana nestas eleições (Brito, 2015). Acreditamos que de fato, seria inútil a integração e criação ou reformas de instituições regionais sem a vontade política que permitissem reformas e ajustes internos. Num contexto de uma intensa globalização econômica, a integração regional constitui uma ferramenta importante na criação de condições para o crescimento, desenvolvimento e unidade sóciopolítica entre os Estados-membros (Balassa,1961). Mas ainda, de uma forma geral, os resultados têm sido constrangedores apesar de o continente africano ter um extenso historial de ações de integração regional.

O problema de integração é transversal a Cabo Verde, visto que o país procura incluir a sua econômia num espaço global seguro e estável, essencialmente pela via de multilateralismo, procurando a mobilização de soluções políticoinstitucionais compreensíveis, capazes de contornar as vulnerabilidades de um Estado insular. Quaisquer que sejam os atores, a visão e o projeto, o processo da integração regional será sempre um processo complexo e lento, que engloba fatores internos que interagem com fatores geo-políticos, econômicos, culturais e religiosos (Tolentino, 2013). Esta realidade tem contribuído de forma direta para uma relação menos conseguida entre Cabo Verde e as organizações sub-regionais, nomeadamente a CEDEAO, onde o arquipélago é um caso de regionalismo africano que, felizmente ou infelizmente, tende a ser cada vez menos, na medida em que a dinâmica política e sócio-cultural "se torna cada vez mais dependente e tributária dos valores da civilização ocidental, tanto os que são importados e incorporados diariamente, como aqueles que estão inscritos no código genético da sua existência enquanto entidade humana" (Silveira, 2005, p. 9).

As complexidades que têm marcado as relações de Cabo Verde com a África, particularmente com a região ocidental, decorrem de um longo processo de internalização e externalização de um habitus, que demonstra a qualidade específica do cosmopolitismo do cabo-verdiano, mas também, a sua proximidade cultural com o ocidente recusando, deste modo, a sua adição no conteúdo 
africano (Furtado, 2013). Com efeito, Cabo Verde apresenta problemas no que se refere a percepção da sua integração regional, pelo fato de a sociedade ter um entendimento ambivalente da sua pertença africana, refugiando-se numa encruzilhada situada entre a África, Europa e as Américas (Tolentino, 2013).

A dimensão do mercado local e fatores de caráter geoestratégico fizeram com que o governo cabo-verdiano se mobilizasse na procura de espaços sub-regionais e projetos de cooperação bilateral e multilateral com o objetivo de contornar os constrangimentos estruturais. A propósito, "a política externa de um pequeno país só pode ser, na verdade, a administração inteligente das suas virtualidades estratégicas" (Macedo, 2006, p. 28). Regista-se no quadro da geo-política, relações privilegiadas de Cabo Verde com potências mundiais como os EUA, UE e China, o que é de todo o modo justo, face às doações (a ajuda pública ao desenvolvimento), empréstimos e investimentos conseguidos até à presente data. Portanto, é natural que Cabo Verde tenha pensado em contornar obstáculos ao desenvolvimento mediante diferentes formas de cooperação geoestratégica, mas não é menos verdade que o mesmo tenha que abrir mão do continente africano, pelo contrário deve e, a curto ou médio prazo reforçar esta relação, já que a importância que Cabo Verde tem hoje a nível internacional, devese, extraordinariamente à sua inserção geográfica na região ocidental africana, de modo que as parceiras estratégicas conseguidas, nomeadamente com a UE, têm na sua base a exigência do reforço da integração na África Ocidental. Esta exigência tem como base o fato de a região apresentar o incentivo dos recursos naturais, o que Ihe pode permitir a adição no comércio internacional com a constituição das cadeias produtivas sólidas.

Mais do que uma exigência a retomada da centralização da geo-política de integração de Cabo Verde na CEDEAO deveria constituir uma estratégia de desenvolvimento e investimento a médio e longo prazo. Porém, esses "só podem ser feitos mediante o diagnóstico minucioso da conjuntura atual e das linhas tendenciais da sua evolução. $\mathrm{O}$ sucesso dos investimentos depende da capacidade de identificar conjunturas potencialmente favoráveis" (Correia e Silva, 1996, p. 54). A estratégia de integração, principalmente econômi$\mathrm{ca}$, não deve ser o meio exclusivo para a promoção do desenvolvimento, mas deve ser acompanhada de um quadro político e institucional de parcerias planejadas a nível nacional, sub-regional e regional (Asante, 1991). É preciso que, num contexto internacional abalado pela crise econômica e financeira que tem afetado os parceiros estratégicos de Cabo Verde, o Estado faça o diagnóstico conjuntural "que possam pôr em perigo a reprodução do processo e tentar relativizar os impactos negativos ou então buscar soluções alternativas" (Correia e Silva, 
1996, p. 54), e neste caso uma das soluções para o arquipélago, seria uma maior projeção e integração regional na CEDEAO.

\section{Notas finais e recomendação geoestratégicas}

No contexto de desenvolvimento sustentável, Cabo Verde, como outros pequenos Estados insulares, precisa de apostar na integração sub-regional, de modo a se beneficiar dos mecanismos de desenvolvimento, de segurança e defesa. As opiniões divergem entre os grupos que discutem a permanência ou a retirada de Cabo Verde da CEDEAO, no entanto reconhece-se que a retirada pode constituir um erro monumental com relação à África. $\mathrm{O}$ primeiro grupo defende que o futuro das relações internacionais de Cabo Verde passa efetivamente pela aposta no continente africano e na adoção das opções estratégicas quanto às vantagens e potencialidades para o seu desenvolvimento. O segundo grupo, por sua vez, defende que a África não deve constituir uma prioridade para as relações internacionais de Cabo Verde, mas que deve continuar a privilegiar a relação com a Europa, Estados Unidos e a China onde o arquipélago deve aproveitar da melhor forma as parcerias. Já o grupo dos moderados são mais sensatos e razoáveis, considerando que as relações internacionais de Cabo Verde devem ser "quadripartidas", onde por um lado, o arquipélago deve reforçar a cooperação com a região africana, aproveitando o fato de que o continente poderá vir a desempenhar nos próximos anos um importante papel para o arquipélago em termos políticos e econômicos, e por outro lado, o mesmo deve continuar a dar uma atenção especial aos parceiros estratégicos, a Europa, os EUA e a China.

Aliada à falta de confiança em África e no seu potencial de oportunidades, consideramos que mais do que uma ausência de vontade política em conhecer a realidade africana, existe uma carência de estudos contínuos sobre os benefícios e riscos de integração de Cabo Verde. Perante esta realidade, confirmando as nossas hipóteses, apresentamos quatro recomendações geoestratégicas que poderão contribuir para o aprofundamento da geo-política de integração de Cabo Verde em África, sem contudo abrir mão das parcerias estratégicas que têm auxiliado o arquipélago no processo de desenvolvimento: [i] Cabo Verde deve, perante a vulnerabilidade e insularidade, apostar numa geo-política que privilegia uma maior integração sub-regional na África, de modo a beneficiar os dois mecanismos - segurança e defesa - da região, fazendo face às ameaças internacionais como o trafico de drogas e o terrorismo. Pois, o arquipélago de Cabo Verde tornou-se numa plataforma na segurança da África Ocidental e num vector geográfico importante no desenvolvimento da parceria Norte-Sul e Sul-Sul; [ii] o arquipélago precisa apostar numa 
geo-política que tenha em conta a sua posição geoestratégica no Atlântico, servindo-se como plataforma de prestação de serviços à CEDEAO, de modo a que os ganhos possam reverter também para o reforço de cooperação com a África; [iii] Cabo Verde deve aproveitar, apesar da crise financeira, o crescimento econômico do continente africano para voltar a centralizar a sua geo-política, com o objetivo de potencializar o Investimento Direto Estrangeiro (IDE), e internacionalizar as empresas através de consórcios, num momento em que o continente africano parece ter recuperado a atenção dos agentes políticos, econômicos e financeiros; [iv] a geo-política de Cabo Verde no continente deve passar estrategicamente pela disputa do espaço geoeconómico (TICs, serviços, etc.) da CEDEAO, promovendo-o, em detrimento do confronto direto com potências africanas (com maiores recursos) na luta de espaços no sentido material.

Encorajamos os demais pesquisadores e académicos a problematizarem este campo de estudo, explorando outras perspectivas e concepções de análise no que se refere a geo-política em Cabo Verde. Este campo de estudo necessita de uma profunda reflexão, perante a escassez de estudos e documentos científicos nacionais, principalmente atualizados. Neste sentido, é preciso articular a literatura nacional com a internacional, procurando estudos que versam sobre outras realidades similares.

\section{REFERÊNCIAS}

Asante, S. K. B. (1991). African Development: Adebayo Adedeji's Alternative Strategies. London: Hans.

Assembléia Nacional (1992). Constituição Da República de Cabo Verde. Praia: Assembléia Nacional.

Backheuser, E. (1952). A geo-política geral e do Brasil. Rio de Janeiro: Bibliex.

Badi, M. K. (2001). A integração Regional na África: Análise Político, Jurídico e Econômico. Cadernos de Ciências Econômicas e Empresariais, 25 (40), 53-97.

Boahen, A. (2010). A África diante do Desafio Colonial. Em Boahen, A. (Org.), História Geral da África VII: África sob a Dominação Colonial, 1880-1935 (pp. 1-20). Brasília: UNESCO.

Brito, J. (2015). Relação Cabo Verde/ África: "Falta vontade política e falta compreender a realidade do continente". Recuperado de: http://www.expressodasilhas.sapo. cv/exclusivo/item/44760-relacaocabo-verde-africa-falta-vontadepolitica-e-falta-compreender-arealidade-do-continente

Correia e Silva, A. L. (1996). Histórias de um Sahel Insular. Praia: Spleen Edições.

Castro, J. (1961). Geopolítica da Fome. São Paulo: Editora Brasiliense. 
Costa, W. M. (2008). Geografia Política e Geopolítica da Fome. São Paulo: Edusp.

Crowl, P. A. (1986). Alfred Thayer Mahan: The Naval Historian. Em Paret, P. (Ed.), Makers of Modern Strategy from Machiavelli to the Nuclear Age (pp. 444-477). Oxford: Clarendon Press.

Defarges, P. M. (2003). Introdução à Geopolítica. Lisboa: Gradiva.

Fernandes, J. P. (2003). A Geopolítica Clássica Revisitada. Nação \& Defesa, 105 (2), 221-244.

Furtado, C. (2013). Cabo Verde e a Integração na África do Oeste: Dissonâncias Discursivas e Identitárias. Em Sarmento, C. \& Costa, S. (Orgs.), Entre a África e a Europa: Nação, Estado e Democracia em Cabo Verde (pp. 623-652). Coimbra: Almedina.

Glassner, M. I. (2003). Political Geography. New York: John Wiley \& Sons.

Graça, C. L. (2014). A Noção do "Pragmatismo" na Política Externa de Cabo Verde: Interesse Nacional e Opções Identitários. Em Delgado, J. P.; Varela, O. \& Costa, S. (Orgs.). As Relações Externas de Cabo Verde: (Re) leituras Contemporâneas (pp. 267-283). Praia: ISCJS.

Ki-Zerbo, J. (2010). Metodologia e Préhistória da África: Historial geral da África I. Brasília: UNESCO.

Korinman, M. (1990). Quand I'Allemagne pensait le monde.
Grandeur et décadence d'une Géopolitique. Paris: Fayard.

Lopes Da Cunha, G. \& Appel, T. N. (2014). Geo-política e trajetórias de desenvolvimento comparados: América do Sul e Leste da Ásia. Revista Científica General José María Córdova, 12 (13), 89-105.

Lourenço, P. L. (2006). Cabo Verde ou da Necessidade de uma Nova Parceria. Nação \& Defesa, 3 (114), 7-14.

Macedo, J. B. de (2006). História Diplomática Portuguesa: Constantes e Linhas de Força. Lisboa: Instituto da Defesa Nacional/Tribuna da História.

Mello, L. I. A. (2015). Quem tem medo da Geopolítica. São Paulo: Hucitec; Edusp.

Mourão, F. A. (2003). O Défice Político da CPLP. O Mundo em Português - A Europa Mundo, IV (45/47), 1920.

Pizzi, J. (2005). O desenvolvimento e suas exigências morais. Obtido na Universidade Católica de Pelotas. Recuperado de: http:// www.ucpel.tche. br/filosofia/vol1/ desenvolvimento.pdf

Reis, V. (2010). Desenvolvimento em Cabo Verde: As Opções Estratégicas e o Investimento Direto Estrangeiro - Contributo Português. Aveiro: Mimographus.

Santos, M. E. M. (2007). História Concisa de Cabo Verde. Lisboa/ Praia: IICT/IIPC. 
Silveira, O. (2005). A Democracia em Cabo Verde. Lisboa: Edições Colibri.

Tolentino, A. C. (2013). A Difícil Integração Africana. Em Sarmento, C. \& Costa, S. (Orgs.), Entre a África e a Europa: Nação, Estado e Democracia em Cabo Verde (pp. 609-622). Coimbra: Almedina.

(2007). Universidade e Transformação Social nos Pequenos Estados em Desenvolvimento: O Caso de Cabo Verde. Lisboa: Fundação Calouste Gulbenkian.

Tuathail, G.; Dalby, S. \& Routledge, P. (2006). The Geopolitics Reader. London: Routledge.
Uzoigwe, G. (2010). Partilha Europeia e a Conquista da África: Um Apanhado Geral. Em Boahen, A. (Org.), História Geral da África VII: África sob a Dominação Colonial, 1880-1935 (pp. 21-50). Brasília: UNESCO.

Visentinl, J. W. (2008). Novas Geopolíticas. São Paulo: Editora Contexto.

Weber, M. (2015). Escritos Políticos. São Paulo: Folha de São Paulo.

Zannou, A. (2010). Determinants of Intra-ECOWAS Trade Flows. African Journal of Business Management, 4 (5), 678-686. 